\title{
Recognising Connections Between Intimate Partner Sexual Violence and Pornography
}

\author{
Laura Tarzia ${ }^{1}$ and Meagan Tyler ${ }^{2}$ (Joint First Authors) \\ ${ }^{1}$ Department of General Practice, The University of Melbourne, Australia \\ ${ }^{2}$ Centre for People, Organisation and Work, RMIT University, Australia
}

\begin{abstract}
In this paper we call for a more concerted effort to understand the ways in which pornography might be used in, and contribute to, intimate partner sexual violence (IPSV). We seek to address this through an overview of existing work and the introduction of data from an Australian-based project on women's experiences of IPSV, where pornography use was an unexpected finding. Furthermore, we argue that there is a pressing need to address such issues now, given the increasing mainstreaming of pornography. Our findings contribute towards a better understanding of the context and dynamics of IPSV for women and suggest that pornography ought to be a greater focus in prevention efforts.
\end{abstract}

\section{INTRODUCTION}

Intimate partner sexual violence (IPSV) is a hidden and poorly understood form of violence against women (Easteal \& McOrmond-Plummer, 2006; McOrmond-Plummer, Easteal \& LevyPeck, 2014; Parkinson \& Reid, 2014). Situated at the intersection between intimate partner violence (IPV) and sexual violence, IPSV incorporates a range of behaviours including rape, sexual assault, and sex obtained via coercion and threats (Bagwell-Gray, Messing \& BaldwinWhite, 2015). IPSV is perpetrated almost exclusively by men, even more so than other forms of IPV, and is the most common form of sexual violence against women (Cox, 2015; Logan, Walker \& Cole, 2015). Estimates suggest that around 10 per cent of women may have experienced IPSV (Bagwell-Gray et al., 2015; Logan et al., 2015; McLindon, Humphreys, \& Hegarty, 2018), however, given the stigma and silence surrounding this issue, it is highly likely that these figures are an under-representation.

Research seeking to understand the specific dynamics of IPSV is scarce (Tarzia, 2020). Although there are important bodies of work exploring causal factors for men's use of sexual violence more broadly (Malmuth, Addison \& Koss, 2000; Peter \& Valkenburg, 2016), as well as for IPV (Abramsky et al., 2011), IPSV is neither "just" sexual violence, nor "just" a form of IPV. Rather, it is a unique phenomenon that incorporates elements of both (Tarzia, 2020). Yet, the IPV literature in the main, has failed to acknowledge the sexual element of IPSV (Cahill, 2001). Similarly, sexual violence scholarship largely overlooks the context of ongoing fear, coercion and control that characterises relationships in which IPSV is present (Logan, 2015). 
In her ecological examination of IPSV, Laura Tarzia (2020) has identified particular factors that contribute to IPSV at the individual, relationship, community and societal levels. Importantly, she suggests that pornography may be one of these factors, both at the level of the individual perpetrator and within wider society. This is an argument that has been widely acknowledged by sexual violence scholars (Foubert et al., 2019) but has not yet permeated the IPV literature to any large extent. Consequently, to date, there is little work specifically addressing the relationship between pornography and IPSV (cf. DeKeseredy \& Hall-Sanchez, 2017). This is a critical oversight given that, as Walter DeKeseredy and Marilyn Corsianos (2016, p. 57) argue, "Pornography plays a key role in women's experiences of male violence in private places." Furthermore, in today's cultural climate there is a need to contextualize women's experiences of IPSV within a pornified culture, where pornography consumption is increasingly normalized and largely legitimized, especially for young men (Dines, 2010; Lim et al., 2016).

In this paper, we unpack the connections between pornography and IPSV through a thematic analysis of qualitative interviews with $n=38$ survivors. While we acknowledge the feminist debates regarding pornography and violence against women, we argue that these should not obfuscate the need to address the accounts of IPSV survivors. Rather, given the ubiquity of pornography, we should expect - as researchers - that pornography will be part of the landscape of heterosexual relations in many places, and more openly explore how women recount and understand the relationship between pornography and their own experiences of abuse. This paper begins with outlines of the relevant literature regarding pornography and violence against women, before focussing on the limited extant literature relating to the specific relationship between pornography and IPSV. There is then a section on the broader context in terms of pornification and the cultural shift around pornography, as well as the shift within mainstream pornographic production and content since the turn of the century. Finally, we move to findings and discussion regarding women's reported experiences of IPSV and pornography from the Beyond Silence study in Australia and call for further research in this area to address potential overlaps and intersections between IPSV and pornography.

\section{Pornography and Violence Against Women}

Pornography ${ }^{1}$ and violence against women have been linked in a variety of ways within an evidence base consisting predominantly of feminist research. This work includes claims that pornography: creates and reinforces a culture in which violence against women is permissible (e.g. Dworkin, 1981; Itzin, 1992; Russell, 1993); that pornography harms women of colour through perpetuating racist and sexist stereotypes (e.g. Bernard, 2016; Collins, 1993); that pornography involves harm to women involved in its production (e.g. Dines et al., 1998; Bridges \& Anton, 2013; MacKinnon, 2006; Tyler, 2015); that pornography - as part of the wider sex industry - is part of a continuum of violence against women (e.g. Dworkin, 1981; Jeffreys, 2009; MacKinnon, 2006), and; that pornography can be used to directly facilitate IPSV (Bergen \& Bogle, 2000; Shope, 2004; DeKeseredy \& Hall-Sanchez, 2017; Russell, 1998). Much of this concern has been founded on an understanding that pornography frequently contains objectifying and dehumanising portrayals of women, as well as regularly including aggression, abuse and 
violence against women ${ }^{2}$. Here we provide some brief context with regard to feminist debates about pornography and violence against women, before considering the evolution of research that has focused on pornography and sexual violence against women. We pay particular attention to research addressing women's experiences of pornography use as a part of IPSV.

\section{A Note on Feminist Debates and Pornography}

It is important to acknowledge that feminist debates about the relationship between pornography and violence against women have been well established for decades, both within and outside of the academy (Boyle, 2000). These debates have often been heated and fractious. It is not our aim here to pass judgement on them, but rather to acknowledge them and emphasise the need to include accounts of women's lived experiences of violence (Bergen \& Bogle, 2000), even if there are also accounts of women having more positive or contradictory relationships to pornography in other contexts (Ashton et al., 2018).

While we acknowledge the important work of feminists who have argued that the pornography industry itself must be seen as part of a continuum of men's sexual violence against women (Dworkin, 1981; Jeffreys, 2009; MacKinnon, 2006), we also wish to note that such a position is not required to recognise the existence of violence against women in mainstream, commercial pornography and associated harms, including the involvement of pornography in IPSV. As the following sections show, there are multifaceted ways in which pornography can be seen as connected to experiences of IPSV, and the following sections consider existing research on pornography as implicated in IPSV, as well as the ways in which we must understand the changing nature of pornography content and consumption.

\section{Pornography and Intimate Partner Sexual Violence}

The extant literature on understanding how pornography facilitates, exacerbates, or perhaps even causes men's sexual violence against women can be crudely split into two broad categories: the first category consists of early non-feminist work that centres around laboratory studies of men's exposure to pornography and subsequent reported attitudinal or behaviour changes, much of which attempts to establish a direct causal relationship (e.g. Donnerstein, \& Berkowitz, 1981; Donnerstein \& Linz, 1986; Feshbach \& Malamuth, 1978; Malamuth, 1981; Zillmann \& Bryant, 1984). For the most part, this work does not address IPSV directly. Within the second category which is our focus here - we find more feminist-informed, and generally more qualitative work. This second set of research engages with women's experiences of coercion, violence and pornography (including the experiences of women harmed in the production of pornography materials) as well as perpetrator reports of the use of pornography in their enacting of violence against women. Within this broader literature is a subset of works that have addressed, specifically, women's experiences of IPSV and pornography.

\section{Feminist-Informed Studies on Women's Experiences}

Feminist scholars have been calling for research in this area to move beyond any attempt to "prove" a simplistic cause-and-effect model for decades (e.g. Boyle, 2000; Cameron \& Frazer, 2000; Russell 1993). Raquel Bergen and Kathleen Bogle (2000) state, with regard to their own 
research, that: "Correlational data do not prove causality. While we cannot say that pornography causes violence against women, this research does provide more evidence about how pornography plays a role in the sexual violence experienced by some women" (p. 232). This summarises a significant proportion of feminist-informed work that seeks to understand a more complex multitude of relationships where pornography is implicated in some forms of men's violence against women, outside a narrow understanding of direct causality.

Debates about direct causality have frequently derailed potentially productive discussions about studies that provide a more qualitative sense of how women experience connections to pornography use in conditions of sexual violence. There is also important work that has explored the connections between pornography consumption and violence against women, as from the perspective of perpetrators (e.g. Jensen, 1998), but - given the focus of this paper - we will specifically consider here, a smaller set of works that look at women's experiences of intimate partner violence and intersections with pornography use. It is important to keep in mind, as noted by DeKeseredy and Corsianos (2016), that such research is relatively rare and, on the whole, work considering sexual violence and pornography use has largely fallen from favour, although this might be changing.

Some of the earliest public accounts of women explaining how they felt harmed or abused through the use of pornography in their intimate relationships occurred during the hearings for the Dworkin-MacKinnon ordinances in the US during the mid-1980s, and women's testimonies recorded for the US Attorney General's Commission on Pornography (also known as the Meese Commission), also during the 1980s. These hearings provided significant evidence that some men use pornography as a tool to manipulate and force women to have certain types of sex, sex that those women report not wanting to engage in (Dworkin \& MacKinnon, 1997; Russell, 1998). In these contexts, many women spoke of how pornography had been used, in a variety of ways, as part of their abuse. Sometimes this took the form of having sexual images taken or distributed without their consent, or explicitly against their will ${ }^{3}$. For others, it was being shown pornography, under threat or coercion and, for others, it was pornography being used by a perpetrator as a kind of manual for carrying out the abuse (see also: Kelly, 1988, p. 110-11, 11617).

This evidence presented at the hearings suggests pornography was being used as a way to groom or coerce wives and girlfriends into accepting certain sex acts. For example, one woman who testified at the Messe Commission stated:

He told me if I loved him, I would do this. And that, as I could see from the things that he read me in the magazines initially, a lot of times women didn't like it, but if I tried enough I would probably like and I would learn to like it (quoted in Russell, 1998, p. 144).

Another woman explained how pornography had been used by her husband to shape their sexual relationship: 
Once we saw an X-rated film that showed anal intercourse. After that he insisted that I try anal intercourse. I agreed to do so, trying to be the available, willing creature that I thought I was supposed to be. I found the experience very painful and told him so. But he kept insisting that we try it again and again (quoted in Russell, 1998, p. 144).

Compared to more contemporary expectations of pornography use and sexual access to women in heterosexual relationships (see Tyler, 2011), these accounts do not seem extreme. Some might even think them to be quite a normal part of heterosexual relations in the current environment, but it is important to keep in mind that women put forward these experiences as being distressing and being experienced as forms of coercion.

Other studies (Bergen \& Bogle, 2000; Shope, 2004) have focused on asking populations of abused women about the perpetrator's consumption of pornography and/or use of pornography as part of any abuse. Bergen \& Bogle (2000) find, for instance that - of those women in their sample who reported knowing that their partner used pornography -40 percent reported that pornography was part of at least one abusive incident. In other examples, women reported a male partner watching pornography before committing an abusive act. Some women were also coerced to have pornography made of them. Janet Shope (2004) finds similar connections: 58 percent of the women surveyed in her study, reported that pornography affected their experiences of abuse. While her work is not qualitative, she notes that in an "attempt to empirically validate the harm of pornography, we have also silenced women's voices and statistically manipulated their bodies. Women's accounts...on the effects of pornography are minimized and/or ignored." (p. 69). Shope therefore calls for more research of the kind we report on in the data and discussion section.

Some research has also considered abused women's experiences of the comparative rates of distressing instances of pornography exposure or consumption, with women who have and have not experienced IPSV (Senn, 1993; Sommers \& Check, 1987). In the available studies, women who were in heterosexual relationships that involved violence (either sexual violence or other forms of assault or abuse) were much more likely to have been shown pornography that they were upset by, or have been exposed to pornography in a way which upset them. Although this suggests some potential connection between pornography and intimate partner violence, such studies can appear almost meaningless in a more contemporary context where pornography exposure is far more ubiquitous, as we discuss further in sections below.

These earlier studies specifically sought out information from participants about pornography use in the context of sexual violence. However, in more recent work by Walter DeKeseredy and Amanda Hall-Sanchez (2017), the connection was not as explicit in the framing of the project. In their research, looking at the abuse endured by rural women during the process of separation and divorce, DeKeseredy and Hall-Sanchez (2017) note frequent references that participants made to pornography. In the initial phase of analysis, it was found that 28 of the 43 women interviewed stated their estranged partners used pornography, and 12 disclosed that pornography was 
specifically involved in their assaults (DeKeseredy \& Hall-Sanchez, 2017, p. 837). The researchers note, however, that the connections were made much clearer when they engaged in a second phase of research - "back talk" - where the participants could speak back to the researchers about their findings. They explain: "[t]hough the back-talk interview schedule did not include specific questions about pornography, most of the participants reported experiences with various types of it" (p. 836). Indeed, more than half reported pornography was involved in their sexual assaults.

As with earlier feminist studies, the participants also reported having pornography made of them and distributed without their knowledge or consent ${ }^{4}$ as well as coercion to watch pornography. There were also accounts that involved imitating what had been seen in pornography, or using pornography as a manual, as well as women linking their experiences of sexual abuse to a partner's use of pornography. For example, one woman describes her experience:

I was asleep one night and he'd been up watching, I don't know what the hell it was, but it was some kind of skin flick. But ah, he would, when he came to bed he, he woke me up by touching me and all that stuff... and I told him to leave me alone and he just, he kept going and um, ended up like shoving, he stuck his fingers inside me and I ended up shoving him out of the bed and I got beat up for that. (DeKeseredy \& Hall-Sanchez, 2017, p. 841)

This study is particularly relevant for our purposes here, as - in latter sections - we offer new data from research on women's experiences of IPSV that also shows women making these direct connections in their own individual experiences.

There can be little doubt that women's reporting of experiences of IPSV and their sense of direct connections to pornography consumption are worthy of further investigation. Not only is this an under-researched area, the limited data that does exist was mostly published 15 years ago, or more (c.f. DeKeseredy \& Hall-Sanchez, 2017). As we explain further, in the following section, in order to truly understand such experiences in contemporary contexts, and in geographical locations such as Australia, it is imperative to consider changes in patterns of pornography consumption, content, and the broader trend of pornification.

\section{Pornification and the Cultural Context of Heterosexual Relations}

We contend that the mainstreaming of pornography is an important cultural shift that must be accounted for in studies of sex and sexuality, including studies of IPSV. The trend of "pornification" has seen the normalization of pornography consumption, particularly for younger men (Lim et al., 2017; Rissel et al., 2016) and has, arguably, also increased the legitimacy of such consumption. At the same time, and as the next section discusses, this shift has coincided with an increase in, and normalization of, "hard core" and/or "gonzo" pornography, which frequently features various forms of aggression, abuse, and violence against women (Dines, 2010; Jensen, 2007; Tyler, 2011). We therefore argue that, in moving beyond a simple cause and 
effect model, it is important to attend to these trends in order to understand the cultural context in which heterosexual relations, including IPSV, take place.

The mainstreaming of pornography in much of the West, since the turn of the 21 st century, has generated a lot of popular and academic interest (Boyle, 2018; Dines, 2010; McNair, 2002; Paul, 2005; Rich, 2001; Tyler \& Quek, 2016). Although there is significant debate about the meaning of this trend, there is widespread agreement that it is occurring. This process is often captured under the term "pornification". A synthesis of existing conceptualisations of pornification shows "an acknowledgment of the encroachment of pornography, and imagery like that promoted by the pornography industry", into everyday life and the ways in which pornography and pornographic imagery are "fragmenting and blurring" into traditionally non-pornographic forms of culture (Tyler \& Quek, 2016, p. 1,5).

The early establishment of "pornification" took place at a time of significant expansion for the mainstream pornography industry, especially in America (Tyler, 2011). While the exact size of the pornography industry in the US remains difficult to ascertain with any great precision, there was widespread agreement, around the turn of the century, that it grossed more than Hollywood and the US popular music industries combined (McNair, 2002; Rich, 2001). Since then, new methods of distribution, coupled with new technology, have facilitated increasing consumption and new patterns of consumption; for example, streaming on smart phones (Lim, 2017). In 2018, for instance, Porn Hub claimed that 80 per cent of all traffic was directed to the site from tablets and smart phones (Porn Hub, 2018). Rather than the previously common representation of pornography as an underground or avant-garde industry, it has become widely considered part of everyday popular culture in the West (Williams, 2007). Therefore, there are two intertwined and important elements of the process of pornification that are especially relevant to understanding potential connections between IPSV and pornography: increasing consumption of pornographic material; and the increasing legitimacy of both pornographic material and its consumption.

Pornification and the porn industry boom laid the foundations for the commonplace nature of the consumption of pornographic material, particularly by young men. In Australia, for example (where the data in following sections was collected), approximately three-quarters of Australian men report having watched pornography in the last year (Rissel et al., 2016). Younger cohorts of men are even more likely to consume pornographic material, with a recent Australian study (Lim et al., 2017) finding 99 per cent of male respondents under 30 years of age report accessing pornography in the previous 12 months. Younger men are also more likely to be habitual consumers of pornography. Lim and colleagues (2017) found, for instance, that 35 per cent of their young, male respondents reported accessing pornography daily and a further 46 per cent reported accessing pornography on a weekly basis. This is particularly concerning given that studies show associations between young men's pornography use, greater rape myth acceptance, and objectification of women (Seabrook, Ward \& Giaccardi, 2019). Although young women are also more likely to be consumers than older women, their consumption patterns differ significantly from young men's: only 4 per cent report daily consumption in the last year (Lim et al., 2016) and 17 per cent report not having accessed any pornographic material at all. 
Moreover, the cultural trend towards normalization has not only meant that consuming pornography is acceptable, but that pornography has become positioned as a cultural authority on sexuality. Pornography is elevated to a status of "how-to" guide in some elements of popular culture, as well as through more medicalised channels such as sex therapy and sexology (Tyler, 2016). Indeed, some sex therapists have gone on record to state they recommend that patients use pornography "like a textbook" (Eberwein, 1999, p. 193). As Tyler (2011) argues, further analysis shows that - even when the content is not explicitly violent - this practice amounts to adding medical authority to a model of sexuality in which heterosexual women are positioned as "sexually servicing" their male partners, rather than being equal partners participating with enthusiastic consent. Such practices signal the potential for a greater coercive cultural environment for pornography use, and the mimicking of acts in pornography within intimate heterosexual relationships. That is, if pornography is presented with this level of normalization and authority it could be limiting the conditions under which women feel able to refuse when partners want to involve pornography or imitate pornography in their own sex lives, with particular implications for lived experiences of IPSV. This issue is of further concern once we consider the content of contemporary mainstream pornography.

\section{Violent and Abusive Content in Mainstream Pornography}

During the shift towards increased pornography consumption, and increasingly normalized pornography consumption, particularly among younger men, there has also been a shift in production and content. During the early 2000s, as the pornification trend was being more prominently documented, there was a shift to "gonzo porn". This is pornography made much more cheaply than older pornographic films and in which there is no plot; the focus is specifically on a series of sex acts. Many, both within the academy and within the porn industry itself, attribute this shift as facilitating more extreme and more violent and abusive sex acts in the porn industry (Tyler, 2011). As with other kinds of pornography (Benard, 2016; Hill Collins, 1993), racism is prominent in "gonzo porn" and is interconnected with its forms of extremity and abuse (Dines, 2006). By the early 2000s, gonzo was one of the most common forms of pornography available on video (Anderson, 2003; Dines, 2010; Jensen, 2007).

Moving forward to the current era of free-to-access online streaming, gonzo is less a new form of pornography, and more an archetype. In a ground-breaking study in 2010, Ana Bridges and colleagues found that in a sample of 304 scenes from best-selling pornography 88.2 per cent contained "physical aggression, principally spanking, gagging, and slapping" and that "perpetrators of aggression were usually male, whereas targets of aggression were overwhelmingly female" (Bridges et al., 2010, p. 1065). They also note that female victims of aggression were often shown in ways that suggested they did not mind what was happening to them, or even that they enjoyed it. This is an important distinction, as some previous studies (e.g. McKee, Lumby \& Albury, 2008) have not coded acts as violent if the target was shown to be enjoying what was done to them and have, therefore, determined that less violence exists. Others claim that, while there is substantial gender inequality represented in pornography (Klaassen \& Peter, 2015) and that violent content exists, it is no longer increasing as a portion of overall 
content (Shor \& Seida, 2019). However, as Jennifer Gosset and Sarah Byrne (2002) point out, in their analysis of internet pornography sites focussing on rape, "[ $t]$ he accessibility of violent pornographic images on the Internet makes questions regarding the proportion of violent pornography less important (p. 705)." That is, in comparison to earlier studies in the 1980s and 1990s, when male consumers had to much more consciously seek out illegal material, the separation between men who sought out violent content and those who did not, was potentially more marked than a context of "someone typing 'rape' on a search engine" (p. 705). It is clear that consumption has increased, as has the accessibility of pornography that depicts aggression and violence and promotes a model of sexuality not commensurate with women's sexual autonomy and equality.

Therefore, it is more important than ever to understand pornography consumption as part of the cultural milieu in which heterosexual relationships take place, and to further analyse the ways in which it is connected to experiences of sexual abuse and violation within heterosexual relationships. The current context in places like Australia, represents a substantial change from the context of earlier works which assumed a clear and determinable difference between cohorts of consumers and non-consumers. Although there are certainly men who do not consume pornography or have consciously chosen to give up consuming pornography (see Tyler \& Jovanovski, forthcoming), this is increasingly rare - particularly among younger cohorts. This makes it increasingly difficult to attribute any specific influence to pornography, because of the level of cultural saturation it has attained. Not only in terms of men's consumption, but also women's consumption, and the more public and legitimising processes of pornification. Furthermore, how pornography is defined and understood may be shifting as a result of its normalisation, creating new challenges for researchers in trying to examine its influence. For example, forms of image-based sexual abuse such as "sexualised photoshopping" may not be understood as pornographic given that we are surrounded by sexualised imagery on a daily basis (McGlynn et al., 2017). This is all the more reason to explore women's lived experiences and the ways that they recognise and define pornography in the context of their sexual relationships. Even though pornography's influence is likely to be under-reported (i.e. many women will not know what constitutes the influence of pornography), it is important information. We must create a space where women feel it is acceptable to share negative experiences of pornography and any connections they have experienced between pornography and IPSV.

\section{METHODS}

\section{The Beyond Silence Study}

The data used in this paper were collected as part of a larger qualitative study, Beyond Silence, exploring women's experiences of IPSV in Australia. Participants were women living in Australia and aged 18 years or older, who self-identified as having experienced unwanted or non-consensual sexual experiences in relationships. What is particularly interesting is that pornography was not directly asked about in this study. Participants were simply given the opportunity to reflect on their experiences of IPSV, with prompting to speculate about their partner's motivations or any underlying causes for the violence. In other words, where pornography was mentioned, it was driven by the participant. Consequently, it is possible that 
the prevalence of pornography use by the participants' male partners, and its impact on their sexual experiences, was higher than suggested by the data. Ethics approval for the study was received from [University] Human Research Ethics Committee [HREC \#1749979].

\section{Recruitment}

Women were recruited via social media (specifically, Facebook and Twitter) using safe methods that have been utilized in several previous studies (Tarzia et al., 2017). Interested women who viewed the study advertisements were able to click through to an online expression of interest form. The form requested that they input their first name, safe telephone number and/or email address (that their abusive partner or other person did not have access to). A research assistant then contacted the women using a generic email (referring to a "Women's Health Study") to confirm interest and provide a copy of the study Plain Language and Consent form.

\section{Data Collection}

Data were collected via unstructured, narrative-style, in-depth interviews, conducted by LT either face-to-face or by telephone. Unstructured or narrative interviews typically involve a single question to set the scene before allowing the participant to tell their story in their own words (Low, 2007). Although follow-up questions (or probes) can be asked by the researcher, it is more akin to a conversation than an interview, and the participant primarily guides the direction and focus (Low, 2007). In this case, women were asked the key question: "Can you tell me about a time in a relationship when something happened sexually that you didn't consent to?" and the research encounter proceeded from there depending on the participant's answers.

The topic of IPSV is highly sensitive and potentially distressing, presenting a challenge to this type of research. Yet, studies consistently indicate that women want to be asked about their experiences and have their voices heard (Valpied et al., 2014). In the event that a woman did become distressed during an interview or at any other time, a protocol was developed to guide the response from the research team. This included referral to appropriate services and the provision of discreet resource cards. Additionally, LT is an experienced interviewer who has worked in the specific area of violence against women for several years and is committed to a safe, woman-centered and ethical approach to research.

The interviews lasted between 22 minutes and 83 minutes (the average was 45 minutes), and were audio recorded and transcribed verbatim for analysis.

\section{Data Analysis}

Braun and Clarke's $(2006,2019)$ reflexive thematic analysis was used to guide the analysis for this paper. Reflexive thematic analysis is an approach in which the subjectivity and reflexivity of the researcher are central (Braun \& Clarke, 2019). LT read and re-read all the transcripts multiple times in order to embed herself in the narratives. Initial descriptive codes were then developed, as well as researcher notes and comments on passages of the text. Following this, descriptive codes were grouped together into interpretative codes, and these in turn were grouped into overarching themes. In reflexive thematic analysis, themes are understood as being shared 
patterns of meaning across a dataset (Braun \& Clarke, 2019) as opposed to being merely descriptive summaries. The preliminary themes were then discussed with MT who has an extensive theoretical knowledge around pornography, and further refined. In keeping with points made by Braun and Clarke (2006), we do not emphasize the relative prevalence of particular themes in the following discussion, but rather aim to show that particular discourses exist.

\section{FINDINGS AND DISCUSSION}

Thirty-eight women participated in an interview. The majority were aged between 18 and 49 years of age, were employed (either full or part-time) and had completed some level of higher education. A third were currently partnered, predominantly with a different partner to the one who had perpetrated the sexual violence. More than half were living with their children. Most of the women spoke English as a first language and did not identify as Aboriginal or Torres Strait Islander. All of the women experienced IPSV perpetrated by a male partner, although the recruitment was open to women in same-sex relationships.

Three main themes - pornography as a sex manual, all about his pleasure, and dehumanizing and devaluing - were developed through an analysis of the interview data describing the relationship between pornography and IPSV. These are described in detail below with supporting quotations.

\section{Pornography as a Sex Manual}

Nearly one in five women specifically described how their partner wanted to "try out" different sexual acts or scenarios that he had seen in pornographic films or on the internet. Some of these participants felt that the consumption of pornography drove their partners to desire more and more violent or graphic sex acts in order to become aroused.

The "empty" [ejaculation] wasn't good enough, it wasn't arousing enough. He was just saturated with all that violent shit from the internet... (Jane)

I have a theory that he is or was one of the guys that watched too much pornography and I don't think that he could get an erection unless he acted out certain things. I think he'd just watched far too much before he partnered with me... and I think he had to do it in order to perform. (Barbara)

Knowing what I know now, he's obviously been watching porn. He's got it [sex act] from there and he's wanted to try it. (Natalie)

Even though he stopped watching porn he still wanted anal sex, but I don't know how strong - I don't know, like I don't know if once the desire is created through watching porn, seeing that as a normal thing, it just stays with you even if you stop watching porn. (Narelle) 
Connected to this was the idea that all women must love sex, be open to experimenting and trying new things. Some of the women's partners used pornography as a way of normalizing their expectations.

I had this idea in my mind that there are women out there that want to have sex all the time and that their partners are very happy... I mean sex is everywhere - in advertising, in movies, not to mention porn. There's that whole thing like men are always checking out boobs. So, there's this idea that they [men] want a lot [of sex]. (Natalie)

I think there's this thing - and I don't know how much but I think maybe quite a bit comes from porn honestly where women are portrayed as being these sort of - they should be a particular way where they're willing to do absolutely everything. (Alice)

It would be verbally saying stuff, like, using pornography to make me think those things were normal, and that's what everybody does. So, like, planting seeds of ideas of this is what you should want to do. (Kate)

Six women described being forced to watch pornography, despite expressing reluctance to do so. For example:

He would make me watch pornography with him that I found very, very demeaning and just made me squirm. He actually wanted to have sex while it was on and I just didn't... I didn't even want to be there let alone do anything else. But there was always that pressure and then he always wanted to introduce toys or different things or in public places. (Eliza)

There were other times where he would try and force me to watch porn with him because he was really sexual and into porn and I'm not. (Chelsea)

He wanted me to watch porn, a lot of gangbanging. Horrible stuff that I'd look at and think, yeah, interesting. Can I read my book now? (Jane)

\begin{abstract}
All About His Pleasure
Beyond the specific connections made by the participants with regard to pornography and their experiences of IPSV, the majority of the women described their sexual relationships as being focused, almost exclusively, on their male partner's pleasure, with their role as servicing his sexual demands. This was usually at a significant cost to them; not just their own pleasure, but their wellbeing and safety.
\end{abstract}

He didn't care if I was crying or he didn't care if I was asleep, or if I was saying no. It was really just, I guess, a selfish thing. I don't know. I don't know. (Krystal)

I knew that he was about to finish and I yelled at him, "Don't! Get off me!" But he finished inside of me against my wishes... But he was "just enjoying himself" and he "didn't mean 
anything by it" and, you know, "oh well it just happened, oh sorry, I was..." - he just didn't want to miss out I guess on his happy ending. (Adele)

He didn't really seem to care that I said I hated it [anal sex]. He'd still ask for it and yeah, you know, I mean, so it kind of, like... That relationship was about four and a half years and probably for the first couple of years I would let him do it maybe three or four times a year, because it was something that he just really wanted, but I hated it. I hated that he didn't care that I hated it. (Corinne)

For many of the women, sex became a site of power and domination, and sometimes part of the sexual turn-on was the woman's reluctance.

[He would make] me feel like I don't have an option but just to service him like I'm a prostitute. (Clare)

It also comes down to not just a sense of entitlement, but also a sense of power. I've got this power over this person, I've got this control over this person, and it's also a sexual turn on for them. (Nadia)

His way of having sex was really quite...He was dominant; he was dominant in that experience and I just didn't like it; I just didn't enjoy it. (Zara)

\section{Dehumanising and Devaluing}

The focus on male pleasure, and the connections participants made between this, male sexual entitlement and domination and power, can also be seen in the way women talked, more specifically, about practices that were overtly dehumanizing or devaluing of them. Within this theme, several women identified the problematic nature of pornography and how it led to women being devalued and dehumanized in wider society.

I think a lot of men just think that we should be like that [porn stars] or else we're not good enough, hot enough, whatever and they have a sort of idea and we're not somehow human to them, I think. Yeah, it's like it sort of dehumanizes us. We're things that are there to be enjoyed perhaps but we're not human. (Alice)

I think porn is a massive issue, something that I thought was cool when we were together, I was like, yeah, I like porn. Everyone likes porn, that's great. But I really do feel like that massively impacts the way that women are treated, especially young women going in and feeling like that's how you should be treated in relationships. (Kate)

In their own relationships, participants described how they were treated as objects to be used sexually, rather than as human beings. 
"I'm only stopping because of the baby," he said. "I'm only stopping because of the baby. But I have a right to your cunt at any time I like. If I want a fucking empty I will have a fucking empty in your cunt." (Jane)

He'd make me give him oral sex and then swallowing and that was just like, oh my God. I wasn't into that at all and even when I was gagging and spitting it out and stuff he was like, yeah alright, whatever. (Faith)

The message that I was clearly getting is, "You are not a sexual or a romantic partner for me. But I will let out my sexual urges on you, by masturbating on you, because that's all you're worthy of." (Romy)

Through sex, the women's male partners sought to degrade them, including filming them.

He got me to make a home video once using a vibrator and then he stored it at his house and my teenage son came across it. (Faith)

He would ring me three, four, five, six times to get me home to give him a blow job. Give him an empty. Give him an empty. That's his language not mine. The physical violence just increased. There was a lot of attempts for anal rape. That's a bit difficult because it's a small hole. But he would just persist. There would be sticks involved for penetration purposes. There would be dog collars that he wanted me to wear. (Jane)

So, we were having sex. He was behind me. He - I must have still had my undies on but that was not normal for me. I don't normally do that... He's come on my back and then he pulled my undies back up over it. It was my only pair of undies. I remember I just burst into tears. I couldn't put my finger on it then, but it was humiliating. That was obviously his intention. (Narelle)

\section{Bringing the Themes Together}

As we outline in earlier sections, the cultural trend of pornifcation means that pornography is a ubiquitous part of life for many men in Australia. While a lesser number of women consume pornography, it is also a part of the sexual lives of many. We need to understand heterosexual relations to be occurring within the context of this broader cultural shift, including experiences of IPSV. In addition, as our discussion below highlights, there is also a need to acknowledge the reflections that survivors of IPSV offer with regard to the influence of pornography and experiences of sexual objectification, humiliation, coercion and violence.

The IPSV survivor participants in the Beyond Silence study recounted being subjected to a variety of acts that they described as demeaning, devaluing, coercive, and violent, and we can understand these as related to, or informed by, pornography in several ways. In some instances, the women interviewed made a clear and direct connection between pornography and the way in which abuse was perpetrated by their partner. This connection is strongest in the "pornography 
as a sex manual" theme. Some women reported recognizing the influence of pornography on behavior and norms, while others spoke of direct experiences of coercion with pornography. In these latter examples, women were not claiming that pornography caused or created the coercion per se, but rather that the pornography was used in the coercion. These reports are similar to the theme of coercion in consumption found by DeKeseredy and Hall-Sanchez (2017).

Women also mentioned pornography being used as a grooming tool (for example: "using pornography to make me think those things were normal") which mirrors accounts in some foundational work in this area (Russell 1998). Several women noted their partner's use of pornography as influencing them and, again, there is a strong resemblance here to the findings in the more recent research from DeKeseredy and Hall-Sanchez (2017) and also earlier work from Bergen \& Bogle (2000). It is worth considering, for further context, that the replication of acts from pornography is not unusual, even among the general population. In one Australian study (McKee et al, 2008), 59\% of respondents reported that they had applied something they had seen in pornography in their own sex lives, and this is coupled with the increasing positioning of pornography as a "cultural authority" on sexuality, as discussed earlier. Therefore, although the debates about correlation and causation with regard to pornography and sexual violence are complex, it is also important to note that many pornography users self-report mimicking pornography. Moreover, given the often aggressive and frequently violent content found in even mainstream, easily accessible pornography - as discussed in the above sections - there should be concerns around consumers self-reporting the influence of pornography in their own sexual behavior.

The more diffuse connections between pornography and violence made by the Beyond Silence participants occurred within descriptions of a sexual relationship in which a male partner's pleasure took precedence, even at the cost of a woman's physical or psychological wellbeing or safety. In the "all about his pleasure theme" women recount being having partners demand sexual acts that they have clearly communicated they "hate", crying during sexual activity, and being raped. Some respondents reflected on such experiences through a broader construction and power dynamics of heterosexuality, including a sense of men's sexual entitlement and sexual desire for control or domination, and an expectation that they "service" their male partners. Although in these quotes the women do not implicate pornography specifically, their accounts bear an almost eerie similarity to feminist critiques of the pornographic construction of heterosexual norms (Tyler, 2011). Such an argument does not suggest pornography creates the problem of sexual coercion or sexual violence, but rather, points out that it shores up an existing narrative that women should be sexually subservient to their male partners, and that this can, in turn, help to create a conducive context for violence against women, including experiences of IPSV.

In a broader cultural environment where men's dominance and women's "service" role is eroticized, it is not surprising that women also report experiences of feeling devalued or objectified. Some of the above accounts are coupled with more overt violence, whereas others recount various acts as having been violations in a number of other ways. One woman explained 
that, on reflection, she understood her partner's motivation as humiliation: Some women also made connections between pornography and a perpetrating partner's sense of sexual norms or sexual scripts (for a discussion of pornography and sexual scripts, see: Sun et al., 2016). That is, they felt pornography was part of the boundary setting for what is considered "normal", and even their own expectations of what was acceptable. As one participant put it: "I really do feel like that [pornography] massively impacts the way that women are treated... and feeling like that's how you should be treated in relationships." While another added: "Yeah, it's like it [pornography] sort of dehumanizes us." Interestingly, these are further instances where, in their own reflections, the women in the Beyond Silence study presented similar perspectives to those put forward in feminist critiques of pornography. In particular, that the objectification and humiliation they reported in their experiences of IPSV, they also saw reflected in pornography.

\section{CONCLUSION}

IPSV is still an under-researched area and this paper has contributed to new work which seeks to understand the role of pornography in "women's experiences of male violence in private places" (DeKeseredy \& Corsianos, 2016, p.57). Direct mentions of, and general reflections about, pornography and pornographic themes were unexpected findings of the Beyond Silence project on women's experiences of IPSV in Australia, in that the interviewer did not ask about pornography and it was not part of the overall project remit. But perhaps such findings should not be, in a more literal sense, unexpected. As we have argued, it is important to understand such findings within the broader context of pornification, increasing pornography consumption (including near universal consumption among younger men), and the frequently aggressive and violent content of mainstream pornography. Indeed, there is likely a need to understand all experiences of IPSV within a context of these trends in any geographic location where pornography is easily accessible, and its consumption is socially acceptable.

Some of our findings echo themes found in the very limited extant literature addressing IPSV and pornography; namely coercion to watch pornography and pornography being used as a "manual" by an abusive male partner. Given these similarities, we call for future IPSV studies to ask survivors about their partner's use of pornography and any perceived connections between experiences of IPSV and pornography. This latter point is of particular interest as the findings here show that some women have reflected on these connections themselves, and their voices should not be excluded from the broader discussions about the ways in which pornography and violence against women can overlap and intersect.

\section{AUTHORS' NOTE}

We would like to thank all the women who participated in this research. Their generosity and resilience are greatly appreciated.

\section{FUNDING}

Laura Tarzia is funded by an Australian Research Council Discovery Early Career Researcher Award (DECRA) - DE170100080 


\section{NOTES}

${ }^{1}$ Following from Dines et al. (1998) we take pornography to be material that is marketed as pornography. This includes, for example - in older contexts - material such as Playboy or Hustler magazines and pornographic films sold in pornography stores. And - in more contemporary contexts - this includes material that is free to access on websites such as PornHub or $X$-Tube, or pay-per-view pornography made by more traditional porn producers such as Wicked Pictures, Vivid Entertainment, Bang Bros etc.

${ }^{2}$ For an analysis of abusive, aggressive and violent themes in contemporary mainstream pornography, see: Bridges et al (2010). For a more theoretical discussion of how pornography can itself be defined as containing these elements, see: Dworkin and MacKinnon (1997).

${ }^{3}$ Something that would more readily be recognized now as 'revenge porn' or image based sexual abuse (IBSA). See, for example: McGlynn et al. (2017).

${ }^{4}$ Again, there are similarities here with what would generally be described as 'revenge porn' or IBSA. Although beyond the scope of this paper, there are certainly cross-overs between the kinds of abuse women describe in the study analyzed in this paper, and the way in which McGlynn et al. (2017) set up - drawing on Liz Kelly's work - a continuum of image based sexual abuse, that warrant further investigation. This is particularly important given that other foundational work in the area of IBSA and the changing nature of technology and sexual violence (e.g. Powell \& Henry, 2017) tends not to engage with issues of commercial pornography and women's experiences of sexual abuse, at all. 


\section{REFERENCES}

Anderson, A. (2003). Harder, Faster, Can Porn get any Nastier? Adult Video News. October. Available from:

https://web.archive.org/web/20050213123151/http://www.adultvideonews.com/cover/cove r1003 03.html Accessed: 31/10/2019.

Ashton, S., McDonald, K., Kirkman, M. (2018). Women's Experiences of Pornography: A systematic review of research methods using qualitative methods. The Journal of Sex Research, 55(3), 334-347. https://10.1080/00224499.2017.1364337

Bagwell-Gray, M. E., Messing, J.T. Baldwin-White, A. (2015). Intimate Partner Sexual Violence: A Review of Terms, Definitions, and Prevalence. Trauma, Violence and Abuse, 16(3), 316-335. https://doi.org/10.1177/1524838014557290

Benard, A. (2016). Colonising Black Female Bodies Within Patriarchal Capitalism: Feminist and human rights perspectives. Sexualisation, Media and Society, 2(4), 1-14. https://doi.org/10.1177/2374623816680622

Bergen, R., Bogle, K. (2000). Exploring the Connection Between Pornography and Sexual Violence. Violence and Victims, 15(3), 227-234.

Boyle, K. (2000). The Pornography Debates: Beyond cause and effect. Women's Studies International Forum 23(2), 187-195.

Boyle, K. (2018). The Implications of Pornification: Pornography, the mainstream and false equivalences. In N. Lombard (Ed.), The Routledge Handbook of Gender and Violence (pp. 85-96). Routledge.

Braun, V., Clarke, V. (2006). Using thematic analysis in psychology. Qualitative Research in Psychology, 3(2), 77-101. https://doi.org/10.1191/1478088706qp063oa

Braun, V., Clarke, V. (2019). Reflecting on reflexive thematic analysis. Qualitative Research in Sport, Exercise and Health, 11(4), 589-597. https://doi.org/10.1080/2159676X.2019.1628806

Bridges, A., Anton, C. (2013). Pornography and Violence Against Women. In J. Sigal and F. Denmark (Eds.), Violence Against Girls and Women: International perspectives (pp 183206). Preager.

Bridges, A., Wosnitzer, R., Scharrer, E., Sun, C., Liberman, R. (2010). Aggression and Sexual Behavior in Best-Selling Pornography Videos: A content analysis update. Violence Against Women, 16(10), 1065-1085. https://doi.org/10.1177/1077801210382866

Cahill, A. (2001). Rethinking Rape. Cornell University Press.

Cameron, D., Frazer, E. (2000). On the Question of Pornography and Sexual Violence: Moving beyond cause and effect. In D. Cornell (Ed.) Feminism and Pornography (pp 240-253). Oxford University Press.

Collins, P.H. (1993). Pornography and Black Women's Bodies. In D. Russell (Ed.) Making Violence Sexy: Feminist views on pornography (pp 97-105). Teachers College Press.

Cox, P. (2015). Violence against women in Australia: Additional analysis of the Australian Bureau of Statistics' Personal Safety Survey 2012. ANROWS Horizons: 01/2015. Retrieved from http://media.aomx.com/anrows.org.au/s3fspublic/151022\%20Horizons\%201.1\%20PSS.pdf 
DeKeseredy, W., Hall-Sanchez, A. (2017). Adult Pornography and Violence Against Women in the Heartland: Results from a rural southeast Ohio study. Violence Against Women, 23(7), 830-849. https://doi.org/10.1177/1077801216648795

DeKeseredy, W., Corsianos, M. (2016). Violence Against Women in Pornography. Routledge.

Dines, G. (2010). Pornland: How pornography has hijacked our sexuality. Beacon.

Dines, G. (2006). The White Man's Burden: Gonzo Pornography and the Construction of Black Masculinity. Yale Journal of Law \& Feminism, 18(1), 283-297

Dines, G., Jensen, R., Russo, A. (1998). Pornography: The production and consumption of inequality. Routledge.

Donnerstein, E., Linz, D. (1986). Mass Media Sexual Violence and Male Viewers: Current theory and research. American Behavioural Scientist, 29(5), 601-618.

https://doi.org/10.1177/000276486029005007

Donnerstein, E., Berkowitz, L. (1981). Victim Reactions in Aggressive Erotic Films as a Factor in Violence Against Women. Journal of Personality and Social Psychology, 41, 710-724. https://doi.org/10.1037//0022-3514.41.4.710

Dworkin, A. (1981). Pornography: Men possessing women. The Women's Press.

Dworkin, A., MacKinnon, C. (1997). In Harm's Way: The pornography and civil rights hearings. Harvard University Press.

Easteal, P., McOrmond-Plummer, L. (2006). Real Rape, Real Pain: Help for women sexually assaulted by male partners. Hybrid Publishers.

Eberwein, R. (1999). Sex Ed: Film, video and the framework of desire. Rutgers University Press.

Feshbach, S., Malamuth, N. (1978). Sex and Aggression: Proving the link. Psychology Today, 12(6): 111-117.

Foubert, J.D., Blanchard, W., Houston, M., Williams, R.R. (2019) Pornography and Sexual Violence. In W. O'Donohue and P. Schewe (Eds.) Handbook of Sexual Assault and Sexual Assault Prevention (pp 109-127). Springer

Gosset, J., Byrne, S. (2002). 'Click Here': A content analysis of internet rape sites. Gender \& Society, 16(5), 689-709. https://doi.org/10.1177/089124302236992

Hegarty, K., Glasziou, P. (2011). Tackling domestic violence: is increasing referral enough? The Lancet, 378(9805), 1788-1795. https://doi.org/10.1016/S0140-6736(11)61386-X

Itzin, C. (Ed.) (1992). Pornography: Women, violence and civil liberties. Oxford University Press.

Jeffreys, S. (2009). The Industrial Vagina: The political economy of the global sex trade. Routledge.

Jensen, R. (1998). Using Pornography. In G. Dines, R. Jensen and A. Russo (Eds.) Pornography: The production and consumption of inequality (pp 101-146). Routledge.

Jensen, R. (2007). Getting Off: Pornography and the end of masculinity. South End Press.

Kelly, L. (1988). Surviving Sexual Violence. Polity Press.

Klaassen, M., Jochen, P. (2015). Gender (In)equality in Internet Pornography: A content analysis of popular pornographic internet videos. The Journal of Sex Research, 52(7), 721-735. https://doi.org/10.1080/00224499.2014.976781 
Lim, M., Agius, P., Carrottee, E., Vella, A., Hellard, M. (2016). Young Australians' Use of Pornography and Associations with Sexual Risk Behaviours. Australian and New Zealand Journal of Public Health, 41(4): 438-443. https://doi.org/10.1111/1753-6405.12678

Logan, T. K., Walker, R., Cole, J. (2015). Silenced Suffering: The need for a better understanding of partner sexual violence. Trauma Violence \& Abuse, 16(2), 111-135. https://doi.org/10.1177/1524838013517560

Low, J. (2007). Unstructured and Semi-structured Interviews in Health Research. In M. Saks \& J. Allsop (Eds.), Researching Health: Qualitative, Quantitative and Mixed Methods (pp 87105). Sage.

MacKinnon, C. (2006). Pornography as Trafficking. In C. MacKinnon Are Women Human? And other international dialogues (pp 247-259). Harvard University Press.

Malamuth, N. (1981). Rape Fantasies as a Function of Repeated Exposure to Filmed Violence Against Women. Journal of Communication, 34(1), 130-147.

McKee, A., Albury, K., Lumby, C. (2008). The Porn Report. Melbourne University Press.

McLindon, E., Humphreys, C., Hegarty, K. (2018). 'It happens to clinicians too': An Australian prevalence study of intimate partner and family violence against health professionals. BMC Women's Health, 18(1), 113-120. https://doi.org/10.1186/s12905-018-0588-y

McNair, B. (2002). Striptease Culture: Sex, media and the democratization of desire. Routledge.

McGlynn, C., Rackey, E., Houghton, R. (2017). Beyond 'Revenge Porn': The continuum of image-based sexual abuse. Feminist Legal Studies 25, 25-47. https://doi.org/10.1007/s10691-017-9343-2

McOrmond-Plummer, L., Easteal, P., Levy-Peck, J. (Eds) (2014). Intimate Partner Sexual Violence: A multidisciplinary guide to improving services and support for survivors of rape and abuse. Jessica Kingsley Publishers.

McOrmond-Plummer, L., Levy-Peck, J., Easteal, P. (2017). Perpetrators of Intimate Partner Sexual Violence: A multidisciplinary approach to prevention, recognition, and intervention. Taylor \& Francis.

Parkinson, D., Reid, S. (2014). 'Invisible' Intimate Partner Violence: Prevention and intervention challenges. In L. McOrmond-Plummer, P. Easteal, \& J. Levy-Peck (Eds), Intimate Partner Sexual Violence: A multidisciplinary guide to improving services and support for survivors of rape and abuse (pp 136-146). Jessica Kingsley Publishers.

Paul, P. (2005). Pornified: How pornography is transforming our lives, our relationships, and our families. Macmillan.

Porn Hub (2018). Year in Review: Devices and technology. Available from: https://www.pornhub.com/insights/2018-year-in-review\#tech Accessed: 30/10/2019

Powell, A., Henry, N (2017). Sexual Violence in a Digital Age. Palgrave.

Rich, F. (2001). Naked capitalists. The New York Times. 20th May.

Rissel, C., Richters, J., de Visser, R., McKee, A., Yeung A., Caruana, R. (2017). A Profile of Pornography Users in Australia: Findings from the second Australian Study of Health and Relationships. The Journal of Sex Research, 54(2), 227-240. https://doi.org/10.1080/00224499.2016.1191597 
Russell, D. (1993). Pornography and Rape: A causal model. In D. Russell (Ed.) Making Violence Sexy: Feminist views on pornography (pp 120-151). Teachers College Press.

Russell, D. (1998). Dangerous Relationships: Pornography, misogyny and rape. Sage Publications.

Seabrook, R.C., Ward, L.M., Giaccardi, S. (2019). Less than human? Media use, objectification of women, and men's acceptance of sexual aggression. Psychology of Violence, 9(5), 536545. https://doi.org/ 10.1037/vio0000198

Senn, C. (1993). The Research on Women and Pornography: The many faces of harm. In D. Russell (Ed.) Making Violence Sexy: Feminist views on pornography (pp 179-194). Teachers College Press.

Shope, J. (2004). When Words Are Not Enough: The search for the effect of pornography on abused women. Violence Against Women, 10(1), 56-72. https://doi.org/10.1177/1077801203256003

Shor, E., Seida, K. (2019). 'Harder and Harder'? Is mainstream pornography becoming increasingly violent and do viewers prefer violent content? Journal of Sex Research, 56(1), 16-28. https://doi.org/10.1080/00224499.2018.1451476

Sommers, E., Check, J. (1987). An Empirical Investigation of the Role of Pornography in the Verbal and Physical Abuse of Women. Violence and Victims, 2(3), 189-209.

Sun, C., Bridges, A., Johnson, J. Ezzell, M. (2016). Pornography and the Male Sexual Script: An analysis of consumption and sexual relations. Archives of Sexual Behavior, 45(4), 983-994. https://doi.org/10.1007/s10508-014-0391-2

Tarzia, L., Valpied, J., Koziol-McLain, J., Glass, N., Hegarty, K. (2017). Methodological and ethical challenges in a web-based randomized controlled trial of a domestic violence intervention. Journal of Medical Internet Research, 19(3), e94. https://doi.org/10.2196/jmir.7039

Tarzia, L. (2020). Toward an Ecological Understanding of Intimate Partner Sexual Violence. Journal of Interpersonal Violence [Online ahead of print 20/01/20]. https://doi.org/10.1177/0886260519900298

Tyler, M. (2011). Selling Sex Short: The pornographic and sexological construction of women's sexuality in the West. Cambridge Scholars Press.

Tyler, M. (2015). Harms of Production: Theorizing pornography as a form of prostitution. Women's Studies International Forum, 48(1), 114-123. https://doi.org/10.1016/j.wsif.2014.11.014

Tyler, M. \& Quek, K. (2016). Conceptualizing Pornographication: Ways forward for feminist analysis. Sexualization, Media, \& Society, 2(2), 1-14. https://doi.org/10.1177/2374623816643281

Valpied, J., Cini, A., O'Doherty, L., Taket, A., Hegarty, K. (2014). 'Sometimes Cathartic. Sometimes Quite Raw': Benefit and harm in an intimate partner violence trial. Aggression and Violent Behavior, 19(6) 673-685. https://doi.org/10.1016/j.avb.2014.09.005

Williams, L. (2007). The Pornography of Consumption / The consumption of pornography. In G. Herdt and C. Howe (Eds.) 21st Century Sexualities: Contemporary issues in health, education and rights (pp 101-107). Routledge. 
Zillmann, D., Bryant, J. (1984). Effects of Massive Exposure to Pornography. In N. Malamuth and E. Donnerstein (Eds.) Pornography and Sexual Aggression (pp 115-138). Academic Press.

\section{BIOGRAPHICAL STATEMENT}

Laura Tarzia is an ARC DECRA Senior Research Fellow in the Department of General Practice, The University of Melbourne. Her inter-disciplinary work focuses on sexual and intimate partner violence against women, with a focus on understanding the dynamics and context of underresearched forms of violence and under-studied populations.

Meagan Tyler is a Senior Lecturer based in the Centre for People, Organisation and Work (CPOW) at RMIT University. Her research focuses on gender equality, men's violence against women and feminist theory. She has published widely on these issues, in a range of contexts, from emergency management to the sex industry and harmful constructions of women's sexuality. 


\section{University Library}

\section{- M M N E R VA A gateway to Melbourne's research publications}

Minerva Access is the Institutional Repository of The University of Melbourne

Author/s:

Tarzia, L;Tyler, M

Title:

Recognizing Connections Between Intimate Partner Sexual Violence and Pornography

Date:

2020-11-23

Citation:

Tarzia, L. \& Tyler, M. (2020). Recognizing Connections Between Intimate Partner Sexual Violence and Pornography. VIOLENCE AGAINST WOMEN, 27 (14), pp.2687-2708. https:// doi.org/10.1177/1077801220971352.

Persistent Link:

http://hdl.handle.net/11343/297297 